\title{
A framework for analysing awe in tourism experiences
}

Alexandra Coghlan ${ }^{\mathrm{a} *}$,

Ralf Buckley ${ }^{\mathrm{b}}$

Dave Weaver $^{\mathrm{a}}$

${ }^{\text {a }}$ Centre for Tourism, Sports and Services Innovation Gold Coast Campus Southport QLD 4222, Australia.

${ }^{\mathrm{b}}$ International Centre for Eco-Tourism Research, Gold Coast Campus Southport QLD 4222, Australia.

a (corresponding author), Centre for Tourism, Sports and Services Innovation Gold Coast Campus Southport QLD 4222, Australia. Tel. +61 (0)7 5552 7368, Fax. +61 (0)7 5552 8895. Email: a.coghlan@griffith.edu.au

To cite this article: Alexandra Coghlan, Ralf Buckley \& Dave Weaver (2012): A framework for analysing awe in tourism experiences, Annals of Tourism Research, 39(3), 1710-1714.

"Awesome" is arguably one of the most highly desirable experiential accolade for both tourists and the providers of those experiences. To achieve this accolade, a tourist product or place must be able to make tourists feel the emotion of awe. Both for commercial tourist marketing purposes and for the analysis of tourism experience, the ability to understand and measure awe is an important yet currently under-researched field. In fact, Holbrook and Hirschman (1982) and Faullant et al. (2011) warn that attendant research in the service literature, including tourism studies, often focus only on higher-order dimensions (pleasurearousal, negative-positive), believed to influence satisfaction, post-visit behaviour, intentions and attitudes, with little attention paid to the full range of affective states described by Russel (1980) and others (e.g. Johnson-Laird \& Oatley, 1989; Otto \& Ritchie, 1996). Here, we set out to establish a framework for the analysis of awe in tourism and identify some of its key components of particular relevance to tourism experiences.

Whilst not included as one of Eckman's (1992) basic emotions, awe is considered to be a "foundational human experience that defines the human existence" (Schneider, 2011, p.249) 
and is pan-cultural in its expression (Konečni, 2005). Awe is elicited through a sense of perceptual vastness and requires cognitive accommodation as one's personal schema is modified to fit novel, unfamiliar information (Keltner \& Haidt, 2003). It remains poorly studied despite its potentially transformative and schema-changing effects (Keltner \& Haidt, 2003; Konečni, 2005; Schneider, 2011; Silvia, 2010). Of particular relevance for tourism is that a sense of awe leads to stronger connections with the surrounding world and a desire to prolong, memorize and/or relive the experience; it leads to behavioural and attitudinal loyalty (Shiota, Keltner \& Mossman, 2007). Whilst there have been no tourism studies that specifically examine awe, its presence in some attractions has been established in the literature, albeit with little consideration of its antecedents or its experiential implications (e.g. Ballantyne, Packer \& Sutherland, 2011; Curtin, 2005, 2009; Fredrickson \& Anderson, 1999; Powell, Brownlee, Kellert \& Ham, 2011; McDonald, Wearing \& Ponting, 2009; Ryan, Hughes \& Chirgwin, 2000; Schanzel \& McIntosh, 2000).

Understanding how the experience of awe by the tourist is transferred to perception of "awesomeness" for an attraction, and what factors can encourage the experience of awe, will require detailed psychological study for large sets of individual tourists. The study presented here proposes a starting framework for this analysis. It used purposive sampling and obtained qualitative data from 55 respondents with particular expertise and experience in tourism research. Data were collected using surveys administered face to face by the first author and via email, until theoretical saturation was reached as determined by data replication and redundancy. Respondents were asked to describe (a) what the term "awe" means for them and (b) describe their most salient memories of experiencing awe as a tourist. We applied an open coding method to identify a single keyword which best encapsulated their response. We then used WordNet 3.1 to analyse the semantics of these codes, and constructed a word cloud based on semantic similarity (Figure 1).

Next, we used axial coding to label a small set of logically distinct words that cannot meaningfully be linked further. These top-tier constructs represent the fundamental components of tourist experiences which lead individuals to consider and recall particular tourist attractions as awesome. The word cloud shows three main groups of words, representing three axial codes. These are physiological response, comparative uniqueness and schema changing components of experiencing awe. Fuzzy boundaries divide the cloud along the axial codes, maintaining clusters of semantically similar words within and between 
boundaries (e.g. "adventurous" combines novelty with daring action, whilst "fabulous" captures the notions of pleasing but also fascinating and exciting). The extracted words substantively correspond with prior research, with specific key words reflecting Schiota et al.'s (2007) schema change and memorisation of the experience, Keltner and Haidt's (2003) need for accommodation, Schneider's (2011) sense of amazement and wonder, and Silvia's (2010) links with novelty and unfamiliarity.

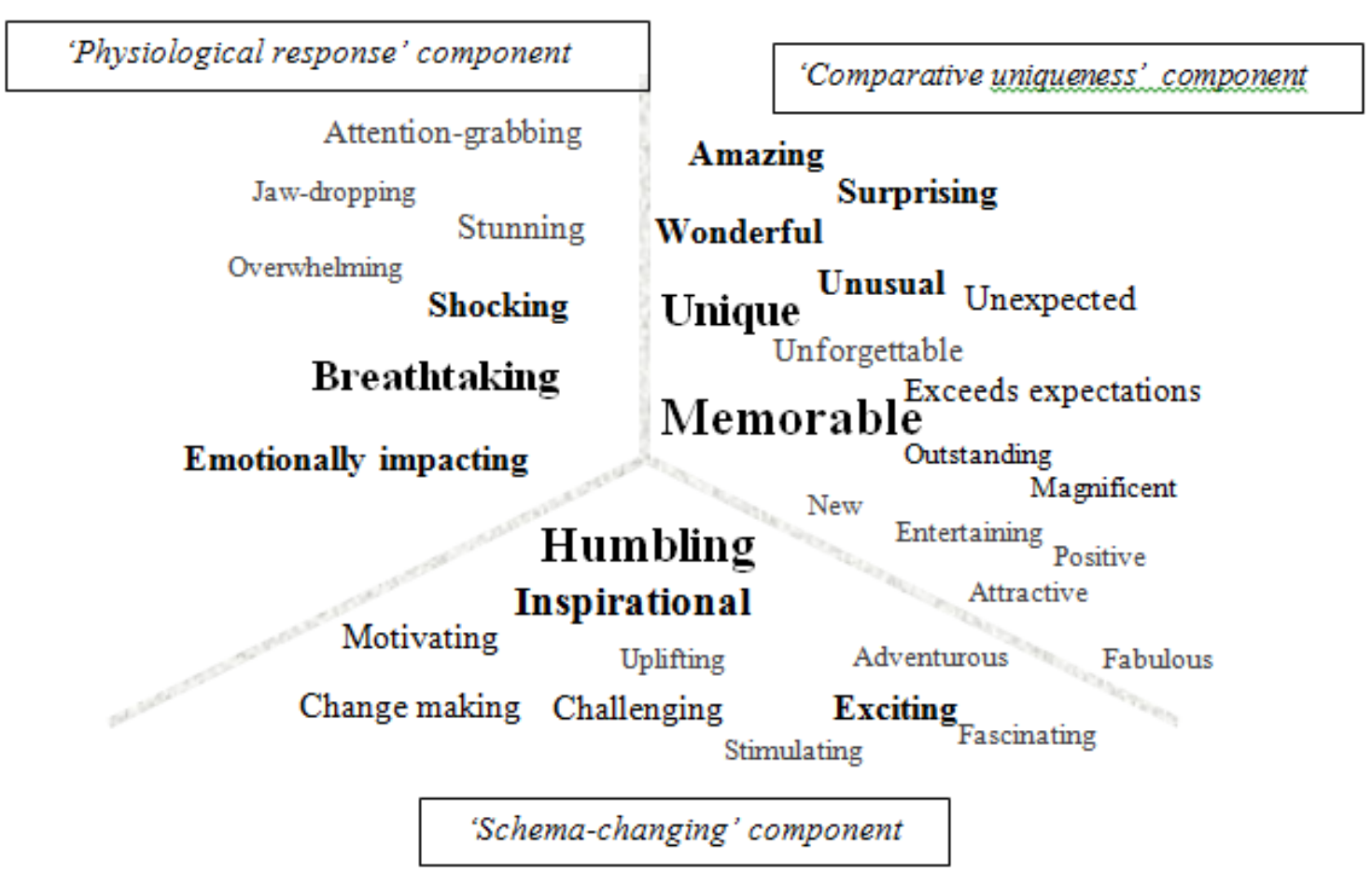

Figure 1. World Cloud representing responses to "Awe-inspiring attractions are...."

In addition, the axial codes described in Figure 1 indicate a temporal aspect in awe; an immediate physiological response, a comparison with past experiences ("this is unique") and a future-oriented, schema-changing component. Whether these three components occur sequentially as described in Figure 2a and whether their effects are simultaneous and either gradual or threshold-based (Figure $2 b$ ) are yet to be determined. These questions have important implications for attitudinal and behavioural loyalty, place attachment and placeprotective behaviour. Place attachment, for example, is a significant theme in protected area management (e.g. Halpenny, 2010). Emotional bonding is well recognised in prior studies, although none have examined which emotions lead to place attachment or considered the role 
of awe in place bonding or place protective behaviour. Finally, emotional responses play an important role in consumer loyalty. Dick and Basu (1994) suggest that "consumers are more likely to engage in word of mouth when they experience notable emotional experiences" (p.107). Future research could address the role of "notable emotions", specifically awe, on tourist behavioural and emotional loyalty, using the three components as an organizational framework.

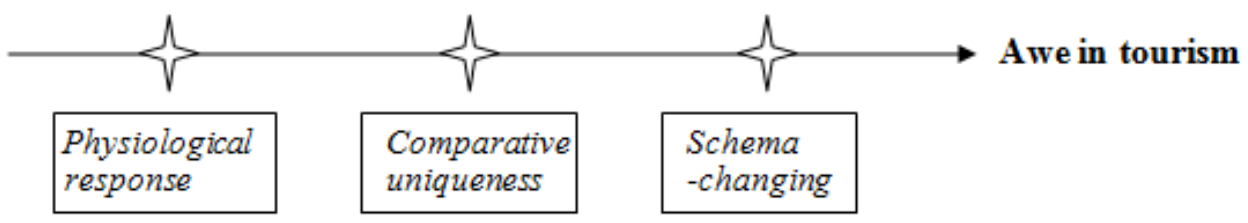

Figure 2a. Sequential model of three key components of awe as experienced by tourists.

Comparative uniqueness

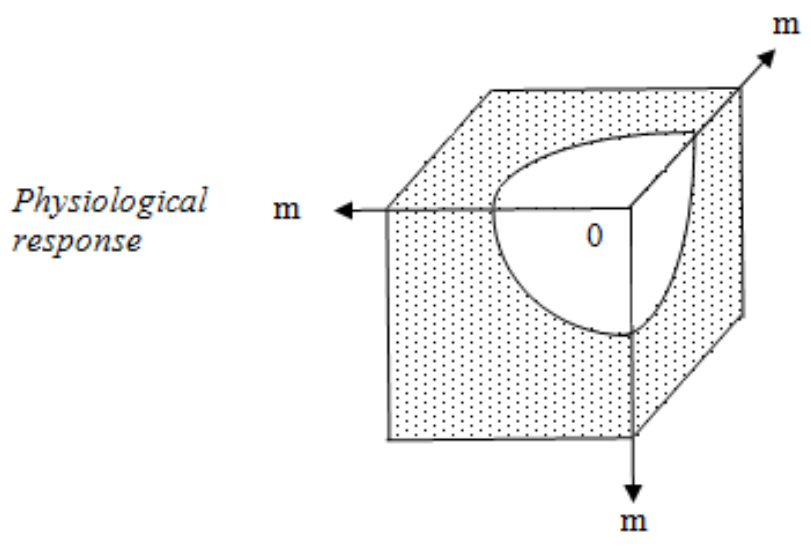

Schema-changing

Figure 2b. Simultaneous-experience model of the three components of awe as experienced by tourists. The 0 at the centre represents no sense of awe, $\mathrm{m}$ represents maximum response humanly possible. The stippled are indicates where awe is present, whilst the blank are indicates the absence of awe. 


\section{References:}

Ballantyne, R., Packer, J. \& Sutherland, L. (2011). Visitor's memories of wildlife tourism: implications for the design of powerful interpretive experiences. Tourism Management, $32,770-779$.

Curtin, S. (2005). Nature, wild animals and tourism. Journal of Ecotourism, 4(1), 1-15.

Curtin, S. (2009). Wildlife tourism: the intangible, psychological benefits of human-wildlife encounters. Current Issues in Tourism 12(5-6), 451-474

Dick, A.S. \& Basu, K. (1994). Customer loyalty: toward an integrated conceptual framework. Journal of the Academy of Marketing Sciences, 22(2), 99-113.

Eckman, P. (1992). Are there basic emotions? Psychological Review, 99, 550-553.

Faullant, R., Matzler, K. \&Mooradian, T.A. (2011). Personality, basic emotions and satisfaction: primary emotions in the mountaineering experience. Tourism Management, 32, 1423-1430.

Fredrickson, J.M. \&Anderson, D.H. (1999). A qualitative exploration of the wilderness experience as a source of spiritual inspiration. Journal of Environmental Psychology, 19, 21-39.

Johnson-Laird, P.N. \& Oatley, K. (1989). The language of emotions: an analysis of a semantic field. Cognition and Emotion, 3(2), 81-123.

Halpenny, E. (2010). Pro-environmental behaviours and park visitors: The effect of place attachment. Journal of Environmental Psychology, 30(4), 409-421.

Holbrook, M.B. \& Hirschman, E.C. (1982). The experiential aspects of consumption: consumer fantasies, feelings and fun. Journal of Consumer Research, 9, 132-140.

Keltner, D. \& Haidt, J. (2003). Approaching awe, a moral, spiritual and aesthetic emotion. Cognition and Emotion, 17(2), 297-314.

Konečni, V. (2005). The aesthetic trinity: awe, being moved, thrill. Bulletin of Psychology and the Arts, 5(2), 27-44.

McDonald, M., Wearing, S. \& Ponting, J. (2009). The nature of peak experience in wilderness. The Humanistic Psychologist, 37, 370-385. 
Otto, J. \& Ritchie, B.J.R. (1996). The service experience in tourism. Tourism Management, 17(3), 165-174.

Powell, R., Brownlee, M., Kellert, S. \& Ham, S. (2011). From awe to satisfaction: immediate affective responses to the Antarctic tourism experience. Polar Record. doi:10.1017/S0032247410000720

Russel, J.A. (1980). A circumplex model of affect. Journal of Personal and Social Psychology, 39(6), 1161-1178.

Ryan, C., Hughes, K. \& Chirgwin, S. (2000). The Gaze, the Spectacle and Ecotourism. Annals of Tourism Research, 27(1), 148-163.

Schanzel, H. \& McIntosh, A. (2000). An insight into the personal and emotive context of wildlife viewing at the penguin place, Otago Peninsula, New Zealand. Journal of Sustainable Tourism, 8(1), 36-53.

Schneider, K.J. (2011). Awakening to an Awe-Based Psychology. The Humanist Psychologist, 39, 247-252.

Shiota, M.N., Keltner, D. \& Mossman, A. (2007). The nature of awe: elicitors, appraisals, and effects on self-concept. Cognition and Emotions, 21(5), 944-963.

Silvia, P. J. (2010). Confusion and Interest: The Role of Knowledge Emotions in Aesthetic Experience. Psychology of Aesthetics, Creativity and the Arts, 4(2), 75-80. 